\title{
ALGUNOS ASPECTOS REPRODUCTIVOS DEL “COCO” Paralonchurus peruanus DE LA COSTA CENTRAL DEL PERÚ
}

\author{
ESPERANZA LÓPEZ \\ HILDA CARAMANTIN
}

Laboratorio de Cordados. Facultad de Ciencias Biológicas. Universidad Ricardo Palma Apdo. 138 Lima-Perú.

\section{RESUMEN}

Se analiza algunos aspectos reproductivos del "coco" (Paralonchurus peruaus) provenientes del Terminal Pesquero de Chorrillos correspondientes a setiembre de 1995 y abril de 1996.

La proporción sexual se determinó utilizando el Test de Chi- cuadrado $\left(\mathrm{X}^{2}\right)$. La talla de primera madurez se obtuvo mediante el método de frecuencia acumulada y la época de reproducción mediante la evolución del índice gonadosomático.

El rango de longitudes para machos estuvo comprendido entre $17 \mathrm{~cm}$ y $36 \mathrm{~cm}$ y para las hembras entre $18 \mathrm{~cm}$ y $32 \mathrm{~cm}$. La proporción sexual fue de 1:1.3 a favor de las hembras. La talla de primera madurez corresponde a $24 \mathrm{~cm}$ de longitud total para ambos sexos; siendo $23.9 \mathrm{~cm}$ para hembras y $24.1 \mathrm{~cm}$ para machos. El índice gonadosomático alcanza los valores más elevados durante los meses de enero y marzo.

\section{SUMMARY}

Some reproductive topics of "coco"Paralonchurus peruanus from Chorillos Fishing Port were analized in the period of September 1995 to April 1996.

The sexual ratio was determined using Chi-cuadrado $\left(\mathrm{X}^{2}\right)$. First maturing lenght was gotten through method of accumulated frequency and the age of reproduction through evolution of gonadal index.

The lenght rankings for male individuals were formed between $17 \mathrm{~cm}$. and $36 \mathrm{~cm}$. and for female indivuals between $18 \mathrm{~cm}$. and 32 $\mathrm{cm}$. The sexual ratio was $1: 1.3$ in favour of female individuals. First maturing lenght was $24 \mathrm{~cm}$ for both sexs; $23.9 \mathrm{~cm}$ for female indivuduals and $24.1 \mathrm{~cm}$. for male indivuals. The gonadal index reached the hightest values during January and March.

\section{INTRODUCCIÓN}

La ictiofauna del Perú cuenta con una diversidad de especies demersales que constituyen uno de los principales componentes en la pesca para el consumo humano directo en el Perú.

Una de las especies demersales es el «coco» Paralonchurus peruanus (STEINDACHNER 1875) que se distribuye en la costa norte y centro del Perú desde Paita hasta el callao.

En el año de 1985 se registró el mayor volumen desembarque (24.588T.), según los reportes de la pesquería marítima del Perú constituyendo el $34 \%$ del total de peces demersales.
Este pez se captura para su consumo, fundamentalmente al estado fresco que es apreciado por su agradable sabor y gran valor nutritivo; asimismo, como fuente de empleo en la pesquería artesanal. Frente a esta situación es necesario realizar estudios de investigación de esta especie orientados a obtener bases científicas en sus aspectos reproductivos que permitirán evaluar y manejar este determinado recurso pesquero.

\section{ANTECEDENTES}

Mollano (1978), Estimó que el "coco" proveniente de Santa Rosa- Lambayeque, alcanza la madurez sexual a una talla de $31.0 \mathrm{~cm}$. 
Gonzáles y Fernández (1991), determinaron que la talla de primera madurez del "coco" en tres áreas de pesca (Paita, Santa Rosa y Callao) fueron de $36.0,32.7$ y $24.0 \mathrm{~cm}$ respectivamente.

\section{MATERIALYMÉTODOS}

El material utilizado para este estudio ha procedido del Terminal pesquero de Chorrillos.

Los muestreos de laboratorio se realizaron desde setiembre de 1995 hasta abril de 1996. Se examinaron 202 ejemplares.

Luego de obtenidas las muestras, se realizaron mediciones y exámenes visuales de cada ejemplar registrándose los siguientes parámetros: longitud total, peso total, peso eviscerado, sexo, estadío sexual, peso de la gónada y longitud de la gónada.

La proporción de sexos se estableció para todo el período de estudio, determinándose la composición en porcentajes del número de machos y de hembras, evaluándose el resultado mediante el test de chi-cuadrado (Nespeira y Gonzáles, 1993).

Para determinar la talla de primera madurez se agruparon los individuos por sexo, calculándose para cada clase de talla el porcentaje de individuos maduros(Estadío III al VIII) respecto al total de ejemplares de su clase. La representación gráfica de los pares evaluados fue ajustada mediante una curva de tipo sigmoide (Mendo 1984).

La época de reproducción se determinó mediante el análisis del índice gonadosomático (Anderson y Gutreuter, 1983), según la siguiente expresión:

\section{$\mathrm{IG}=$ Peso Gonada/Peso Eviscerado*100}

Donde:

IG= Indice Gonadosomático

\section{RESULTADOS}

\section{PROPORCIÓN DE SEXOS}

Durante el período de estudio el rango de tallas estuvo comprendido entre $l o s 17 \mathrm{~cm}$ y $36 \mathrm{~cm}$ de longitud.

La proporción de sexos fue de $1: 13\left(\mathrm{x}^{2}=6.5\right)$, no presentándose ninguna diferencia significativa entre el número de machos y hembras (Tabla 1).

\section{TABLA 1}

VALOR DEL TEST DE CHI-CUADRO POR MESES DURANTESETIEMBRE(1995)-ABRIL(1996)

\begin{tabular}{|c|c|c|c|c|c|}
\hline Missirs & $\begin{array}{l}\text { TOTA. } \\
\text { DE: } \\
\text { WHLARE }\end{array}$ & "1 & $n$ & $\begin{array}{c}\text { cil } \\
\text { ctusirino }\end{array}$ & Proser \\
\hline SET. & 50 & 33 & 17 & 51 & 3.84 \\
\hline OCT. & 25 & 14 & 11 & 0.3 & 3.84 \\
\hline NOV. & 25 & 16 & 9 & 2.0 & 3.84 \\
\hline DIC. & 22 & 14 & 8 & 1.2 & 3.84 \\
\hline ENE. & 21 & 7 & 14 & 2.3 & 3.84 \\
\hline FEB. & - & - & - & - & 3.84 \\
\hline MAR. & 27 & 2 & 25 & 19.6 & 3.84 \\
\hline ABR. & 32 & 27 & 5 & 15.1 & 3.84 \\
\hline TOTAL & 202 & 113 & 89 & 6.5 & 3.84 \\
\hline
\end{tabular}

$x^{2}=3.84$

Con relación a la proporción por longitudes el valor del Test del Chi- cuadrado reveló un mayor valor para las longitudes de 22 y $24 \mathrm{~cm}$ (Tabla 2).

\section{TABLA 2}

VALOR DEL TEST DE CHI-CUADRADO EN RELACIÓN A LA TALLA

DURANTE SETIEMBRE. (1995)-ABRIL. (1996)

\begin{tabular}{|llllll|}
\hline LOG. & $\begin{array}{c}\text { TOTAL, } \\
\text { EIEMLARES }\end{array}$ & H & N & \multicolumn{1}{c|}{$\begin{array}{l}\text { CHI } \\
\text { CuADRMO }\end{array}$} & P. $95 \%$ \\
\hline 17 & 3 & - & 3 & 0 & 3.84 \\
18 & 5 & 2 & 3 & 0.2 & 3.84 \\
19 & 6 & 2 & 4 & 0.6 & 3.84 \\
20 & 6 & 3 & 3 & 0 & 3.84 \\
21 & 13 & 5 & 8 & 0.6 & 3.84 \\
22 & 17 & 13 & 14 & 4.8 & 3.84 \\
23 & 33 & 17 & 16 & 0.03 & 3.84 \\
24 & 22 & 19 & 3 & 11.6 & 3.84 \\
25 & 16 & 8 & 8 & 0 & 3.84 \\
26 & 15 & 9 & 6 & 0.6 & 3.84 \\
27 & 14 & 10 & 4 & 0.8 & 3.84 \\
28 & 11 & 4 & 7 & 0.8 & 3.84 \\
29 & 10 & 4 & 6 & 0.4 & 3.84 \\
30 & 21 & 9 & 12 & 0.4 & 3.84 \\
31 & 4 & 1 & 3 & 1 & 3.84 \\
32 & 5 & 5 & - & 0 & 3.84 \\
36 & 5 & - & 1 & 0 & 3.84 \\
TOTAL & 202 & 113 & 89 & 1.5 & 3.84 \\
\hline
\end{tabular}




\section{TALLADELAPRIMERAMADUREZ}

La talla de primera madurez corresponde aproximadamente a los $24 \mathrm{~cm}$ de longitud total para ambos sexos (23.9 cm para hembras y $24.1 \mathrm{~cm}$ para machos) (Fig.1, Fig.2 y Fig.3). Los primeros ejemplares considerados maduros (estadio III) se encuentran a partir de $10 \mathrm{~s} 17 \mathrm{~cm}$. de talla.

Fig. 1

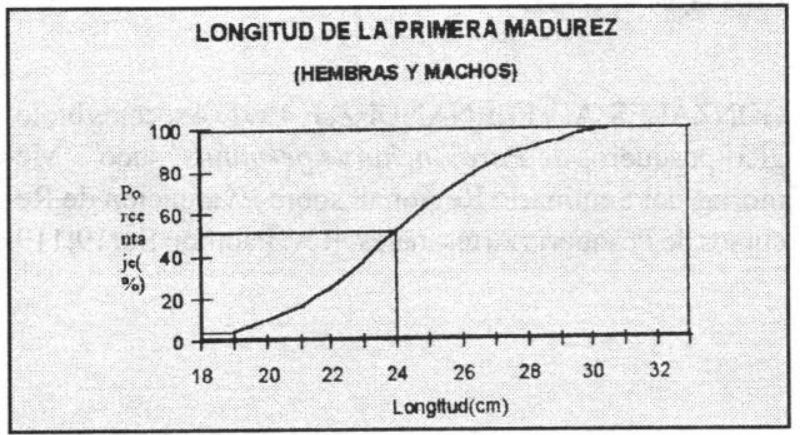

Fig. 2

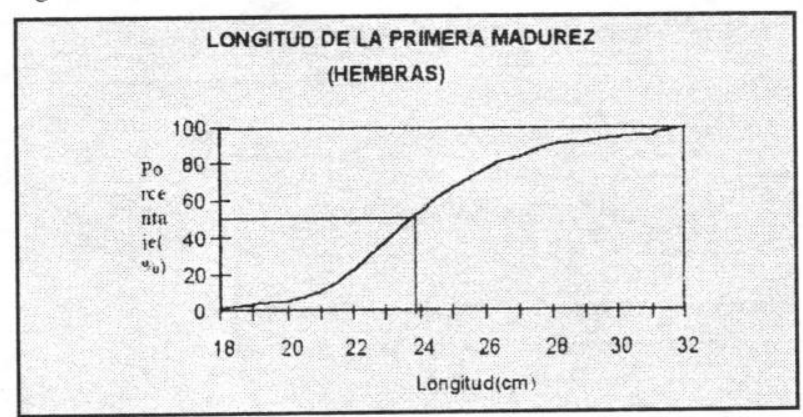

Fig. 3

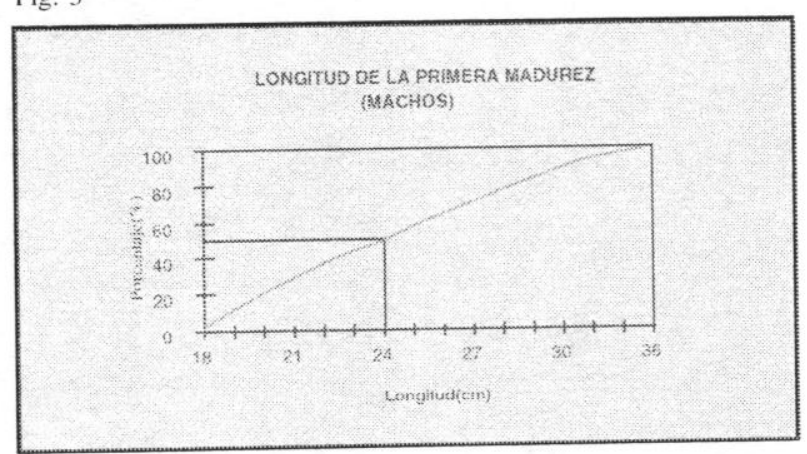

\section{INDICE GONADOSOMATICO}

El índice gonadosomático calculado para hembras y machos alcanza los mayores valores durante los meses de enero y marzo (Tabla 3 y Fig. 4).

Fig. 4

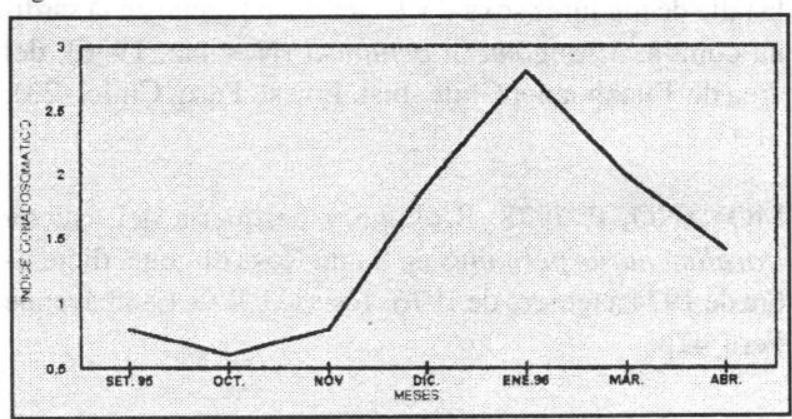

TABLA 3

EVOLUCIÓN MENSUAL DEL ÍNDICE GONADOSOMÁTICO

MESES

IG

SETIEMBRE 95

0.80

OCTUBRE

0.60

NOVIEMBRE

0.80

DICIEMBRE

1.90

ENERO

2.80

MARZO

1.98

ABRIL

1.40

\section{CONCLUSIONES}

* El Test de Chi-Cuadrado demuestra que el « coco» no presenta una desviación significante (al nivel del 95\%) entre el número de machos y hembras.

* La talla de primera madurez para hembras y machos fue de $24 \mathrm{~cm}$ para ambos sexos siendo 23.9 para hembras y $24.1 \mathrm{~cm}$. para machos.

* La época de desove alcanza los mayores valores durante los meses de enero y marzo. 


\section{REFERENCIAS BIBLIOGRÁFICAS}

ANDERSON, H. y CUBILLOS, L. 1994. Determinación de la talla de madurez sexual y fecundidad parcial en la sardina común, Strangomera bentincki (Norman, 1936), del área de Talcahuano, Chile. Inst. Invest. Pesq. Chile, (23): 11-17.

MOYANO, P. 1978. Biología y pesquería del «suco» Paralonchurus peruanus en Santa Rosa durante, diciembre de 1974 a febrero de 1976. Tesis U.P.R.G, Lambayeque Perú, 47p.

MENDO, J. 1984, Edad crecimiento y algunos aspectos reproductivos y alimenticios de la «caballa» Scomber japonicus peruanus. Bol. Inst. Mar Perú-Callao, Perú, 8(4):101-156.

NESPEIRA, L. y Gonzáles, M. 1993. Determinación de la talla de primera madurez sexual y período reproductivo de la «caballa» de las Islas Canarias. Bol. Inst. Espa. Oceanogr. España, 9(1): 15-21.

GONZÁLES, A. y FERNÁNDEZ, F. 1991. Aspectos biológico-pesqueros de Paralonchurus peruanus "suco". Memorias del Seminario Regional sobre Evaluación de Recursos de Pesquería Artesanales, Rev. Pacífico Sur 19:119- 